\title{
Physico-Chemical Properties of Different Juices Orange, Tomato, Carrot and Pineapple
}

\author{
Chaudhary Moni ${ }^{1}$, Mishra Sunita ${ }^{2}$ \\ ${ }^{1}$ Student, Department of Food and Nutrition, School for Home Sciences, Babasaheb Bhimrao Ambedkar University (A Central University) \\ Vidya Vihar, Rae Bareli Road, Lucknow- 226025(U.P.), India \\ ${ }^{2}$ Professor (Dean \& Head), Department of Food and Nutrition, School for Home Sciences, Babasaheb Bhimrao Ambedkar University (A \\ Central University) Vidya Vihar, Rae Bareli Road, Lucknow- 226025(U.P.), India
}

\begin{abstract}
The study was carried out to determine the physic- chemical properties of mock tail juice produced from orange, tomatoes, carrot, pineapple. Smoothies \& juices were developed by blending selected tropical Indian fruits pulps/juices. Fruit pulps from orange, tomato, carrot and pineapple juices were blended at various proportions by considering four individual properties such as pulpy, juicy, sweetness, sourness and colour to yield palatable smoothies without addition of external sugar and acidulant. Study the physic- chemical composition of fresh tomato, orange, carrot, pineapple and to standardize the recipe for orange, tomato, carrot, pineapple. Analysis such as total soluble solids, titratable acidity lycopene, vitamins $A, C$ minerals and fibre, content.
\end{abstract}

Keywords: Blending juices, physic- chemical properties

\section{Introduction}

Fruits contain little or no protein or fat, with most of their energy coming from carbohydrate. The carbohydrate in fruits is usually in the form of the sugars fructose and glucose, although some under-ripe fruits, such as bananas, also supply starch. The sugars in fruits give them their sweetness, while a variety of organic acids, such as citric or malic acid,

Provide the refreshing edge. As fruits ripen, the concentration of sugars rises, while that of acids falls. Fruits supply vitamin $\mathrm{C}$, some B vitamins, and good amounts of potassium and fibre, along with protective phytonutrients. There is a growing body of compelling evidence to suggest that a good intake of fruits can fortify the body against a variety of degenerative diseases. Fresh fruit juices and drinks made from blended fruits count towards the daily recommended intake of five servings, or $400 \mathrm{~g}$ (raw weight), of fresh fruits and vegetables. Fruit teas may, however, lose some value if the temperature of the water is high. Fresh, unsweetened fruit juices are the healthiest and, diluted with water, make a refreshing and healthy drink.fruit juices are liquid, non- alcoholic products with certain degree of clarity and viscosity obtained through pressing or breaking up of fruits with or without sugar or carbon dioxide addition. Fruits and its juices constitute one of the most important foods for man. Their regular consumption maintains health and makes up for the losses in the human diet recommended the consumption of juices with pulp from foods and medicinal points of view. Fruits being a seasonal crop by nature have prompted many researches on how to process fruit juices and preserve them for usage during off season. Nutritional chemical composition and the effect of storage on various fruit (orange, tomato, carrot, pineapple) and four juices.

Mixed drinks is a blended mixed beverage that requires blending possibly one sort of liquor with juices, soda pop and different natural products or blending numerous mixed beverages with juices or ice tea. Mock tail is any blended beverage that does not have liquor. The name mock tail is determined "false" intending to "mimic or copy" alluding to mock tails emulating a mixed drink as it appears to be fundamentally the same as a mixed drink yet does not have liquor or some other spirits. Afterwards is a well known past-time drink that is being devoured by numerous individuals. It is an extremely famous social action that is done at all times. Wine and Beer is expended at all seasons of the day. It is additionally utilized an ice breaker when meeting new individuals.

Orange has a good production potential and suitable for the production of a variety of products with good taste and flavour. The overall acceptability is not good in the beverages due to the lack of pleasing colour. To overcome this problem these can be blended with fruit pulp rich in colour and have good acceptability. The fruits have excellent colour due to the presence of anthocyanins, phenols and betalains in the pulp. Both these anthocyanins and phenols are promising antioxidants. Dietary trends currently emphasis on safe and healthy foods and extend to searches for new components with more than just nutritive value.

As with other citrus fruits, orange pulp is an excellent source of vitamin C. Oranges are full of vitamin $C$, which protects cells by neutralizing free radicals. Free radicals cause chronic diseases, like cancer and heart disease.

Tomato (Lycopersicon esculentum) is one of the most popular and demanding vegetables. Ripe red tomatoes are rich in beta carotene and the anti-oxidant lycopene. Many studies have shown tomatoes inhibit cancer cells, and are effective against a wide range of cancers, help to blood purifying prevent dangerous blood clots, cleans liver, and help to fight gallstones, reduce cholesterol, protect the skin from sunburn, and premature aging.

Carrot is a root vegetable that is often claimed to be the perfect health food. It is crunchy, tasty and highly 


\section{International Journal of Science and Research (IJSR) \\ ISSN (Online): 2319-7064}

Index Copernicus Value (2016): 79.57 | Impact Factor (2015): 6.391

nutritious. Carrots are a particularly good source of betacarotene, fibre, vitamin $\mathrm{K}$, potassium and antioxidants .The carrot gets its characteristic, bright orange colour from $\beta$ carotene, and lesser amounts of $\alpha$-carotene, $\gamma$-carotene, lutein and $\alpha$ - and $\beta$-carotenes are partly metabolized into vitamin A. Carrot and carrot juice benefits that we know about today. Many studies have shown that beta carotene is crucial for improving immunity in the body, protecting skin and eye health, and fighting free radical damage that can cause various forms of chronic diseases.

Pineapples are a delicious tropical fruit that have been celebrated for centuries not only for their distinct and unique taste, but also for their seemingly miraculous health benefits. Pineapple juice, a best nutrient rich juice among all fruit juices, provides lots of health benefits because of its high quantity of minerals, fibres, enzymes, vitamin $\mathrm{C}$ and energy. Their health and medicinal benefits include their ability to improve respiratory health, cure coughs and colds, improve digestion, help you lose weight, strengthen bones, improve oral health, boost eye health, reduce inflammation, prevent cancer, improve heart health, fight off infections and parasites, improve the immune system and increase circulation.

Thus, the study aimed, through mixture design and response surface methodology, to optimize a reduced calorie mixed juice of persimmon, orange, tomato, carrot and pineapple based on sensory and nutritional characteristics. This study also aimed to carry out a survey of the physicochemical characteristics that are desirable in this product.

- To study the physio-chemical properties of different juices.

- To study the sensory quality attributes of tomato juice, orange juice Carrot \& pineapple juice.

\section{Material \& Methods}

In this section we discussed about the materials and methodology used for the development and quality testing of blended juice.

\section{Raw Materials}

Fleshy green orange, tomato, carrot, and pineapple or leaves were collected from a local garden in Luck now. Synthetic colour, flavour, Sugar, sprite, soda, salt, and mint leaves, ice, used in the preparation of juices.

\section{Experimental design}

In this study, a centroid mixture design was used to evaluate the effects and to optimize the proportions of orange (A1), tomato (A2), carrot (A3) and pineapple (A4) in the juices based on their nutritiona land sensory characteristics.

\section{Preparation of Different Types of Juices}

Fresh fruit and vegetables (orange, tomato, carrot, and pineapple) were collected and washed with potable water and cleaned properly. The fruit and vegetables were then sliced/ chopped and blended separately in the electrical blender. The juice was then obtained after filtering. Then each four types of juice were then heated separately for 2-3 minutes, and cooled down at room temperature. The mixed fruits and vegetable juices were then prepared as per the formulation.

The stated amount of sugar, citric acid, thickening agent and water were mixed properly. The mixture was then boiled for about prepare the syrup. The prepared syrup was filtered through cheese cloth and then cooled. The prepared juices of individual fruits were weighed and mixed and KMS were then mixed with syrup and then homogenized the whole mixture using a pressure homogenizer for about 5 to $10 \mathrm{~min}$ to obtain the ready to serve mixed fruits juice. The prepared juices were packed into sterilized bottles through sterilized funnels keeping head space about $2 \mathrm{~cm}$. The bottles were then capped and sealed tightly and stored both at room temperature and refrigeration temperature.

\section{Preparation of Juices}

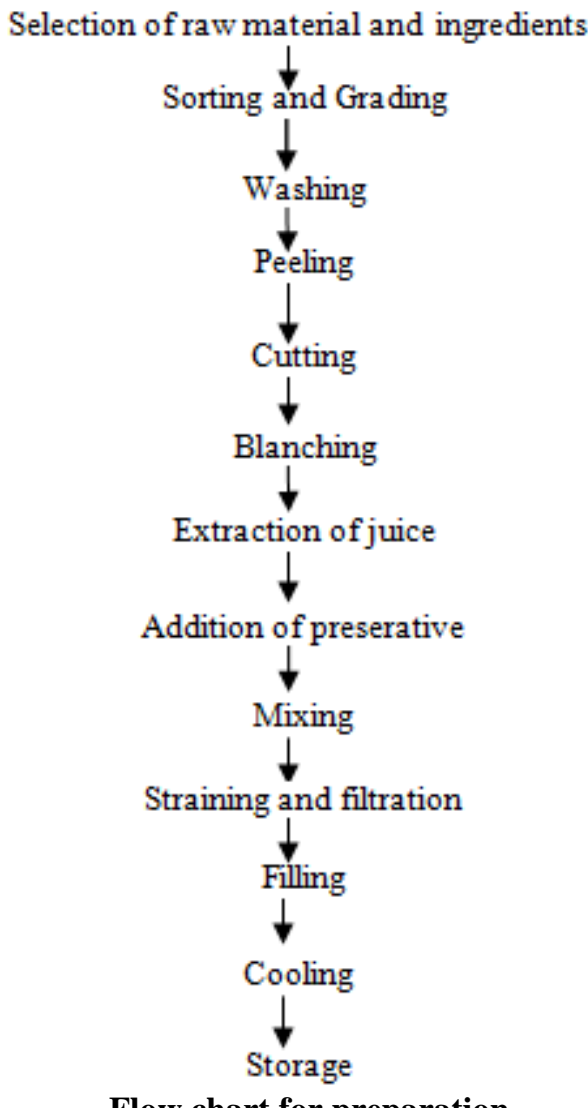

Flow chart for preparation

Physico - chemical evaluation - The next phase involved Physic- chemical evaluation of the prepared orange, tomato, carrot and pineapple juice blended involving different parameters like.

- Estimation of vitamin c

- Estimation of potassium

\section{Result and Discussion}

The experiment was conducted to determine the effective means of processing and preservation of fruit and mixed vegetable juice from orange, tomato, carrot, pineapple . fruit and Vegetable juice was studied for their acceptability and shelf life at room temperature $\left(28-30^{\circ} \mathrm{C}\right)$ and at refrigeration temperature $\left(4^{\circ} \mathrm{C}\right)$. The acceptability and shelf life were evaluated through organoleptic taste testing procedure.

\section{Volume 6 Issue 12, December 2017}

\section{www.ijsr.net}


Sensory Analysis -

The experimental blended beverages were sensory evaluated by a panel of five members on a 9-point hedonic scale and marking was done on the basis of four parameters -

- Body and Texture

- Color and Appearance

- Flavor and Taste

- Overall Acceptability

Paremeter- 1

Flavor and Taste

Table: Individual Markings for Flavour And Tast

\begin{tabular}{|c|c|c|c|c|}
\hline Sample & A1 & A2 & A3 & A4 \\
\hline Member 1 & 9 & 8 & 9 & 4 \\
\hline Member 2 & 8 & 6 & 8 & 7 \\
\hline Member 3 & 8 & 7 & 8 & 7 \\
\hline Member 4 & 8 & 6 & 6 & 7 \\
\hline Member 5 & 9 & 7 & 7 & 5 \\
\hline TOTAL & 42 & 34 & 38 & 30 \\
\hline
\end{tabular}

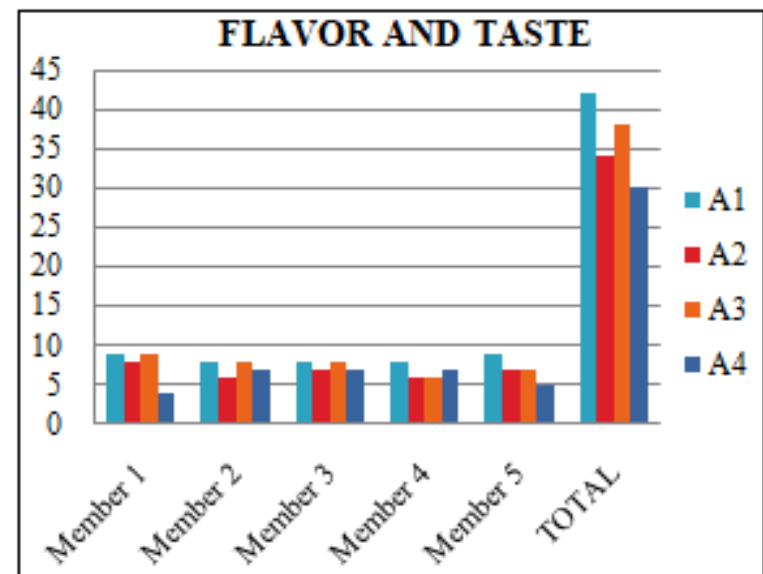

Figure: Graphical Representation of Scores For Flavour And Taste

The above mentioned score represents individual markings by members on the basis of flavour and taste the minimum average scored is 30 by A4 while maximum is of A1 with an average of 42 .

\section{Paremeter -2}

Body and Texture

Table: Individual Markings For Body And Texture

\begin{tabular}{|c|c|c|c|c|}
\hline sample & A1 & A2 & A3 & A4 \\
\hline Member 1 & 8 & 6 & 9 & 4 \\
\hline Member 2 & 7 & 6 & 8 & 7 \\
\hline Member 3 & 8 & 8 & 8 & 7 \\
\hline Member 4 & 9 & 7 & 6 & 7 \\
\hline Member 5 & 8 & 7 & 7 & 6 \\
\hline TOTAL & 40 & 34 & 38 & 30 \\
\hline
\end{tabular}

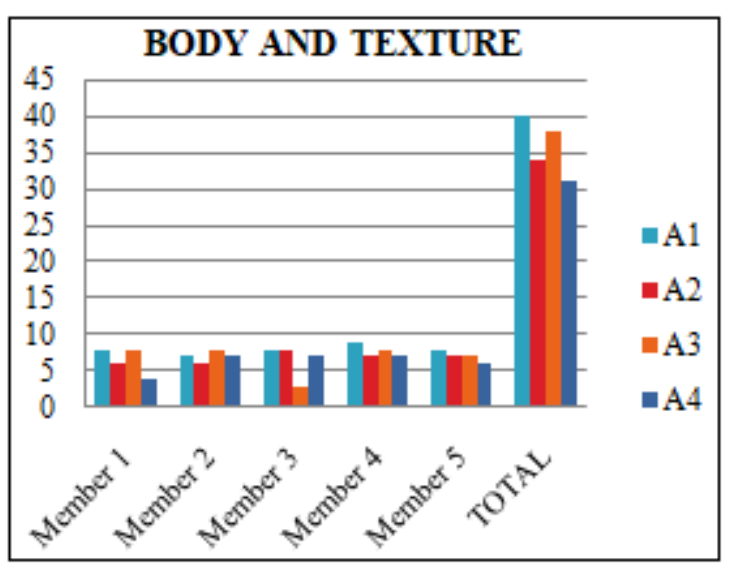

Figure: Graphical Representation Of Scores For Body And Texture

The above graph represents the scores for body and texture the minimum average scored is 31 by $\mathrm{A} 4$ while maximum is of A1 with an average of 40 .

\section{Paremeter- 3}

Colour and appearance

Table- Individual Markings for Colour and Appearance

\begin{tabular}{|c|c|c|c|c|}
\hline sample & A1 & A2 & A3 & A4 \\
\hline Member 1 & 9 & 8 & 7 & 7 \\
\hline Member 2 & 8 & 8 & 7 & 7 \\
\hline Member 3 & 9 & 7 & 8 & 7 \\
\hline Member 4 & 9 & 8 & 7 & 6 \\
\hline Member 5 & 8 & 5 & 7 & 7 \\
\hline Total & 43 & 36 & 36 & 34 \\
\hline
\end{tabular}

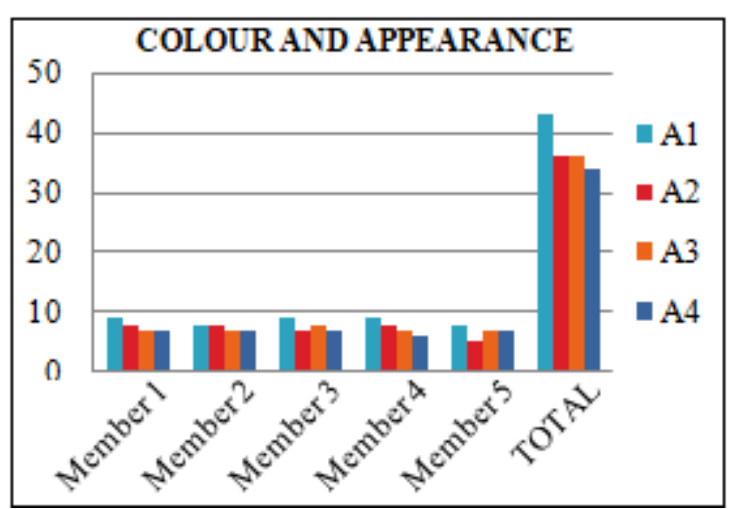

Fig: Graphical Representation of Scores For Colour And Appearance

The average score for colour and appearance the maximum average score 43 by A1 and the least score is for A4 which is 34 , the colour and appearance is highly affected by the concentration of blended beverages.

\section{Paremeter -4}

Overall accepltability

Table: Individual Markings For Overall Accepltability

\begin{tabular}{|c|c|c|c|c|}
\hline sample & A1 & A2 & A3 & A4 \\
\hline Member 1 & 9 & 5 & 8 & 7 \\
\hline Member 2 & 9 & 7 & 8 & 7 \\
\hline Member 3 & 8 & 7 & 7 & 6 \\
\hline Member 4 & 9 & 8 & 7 & 7 \\
\hline Member 5 & 8 & 7 & 8 & 6 \\
\hline Total & 43 & 34 & 38 & 33 \\
\hline
\end{tabular}

\section{Volume 6 Issue 12, December 2017}




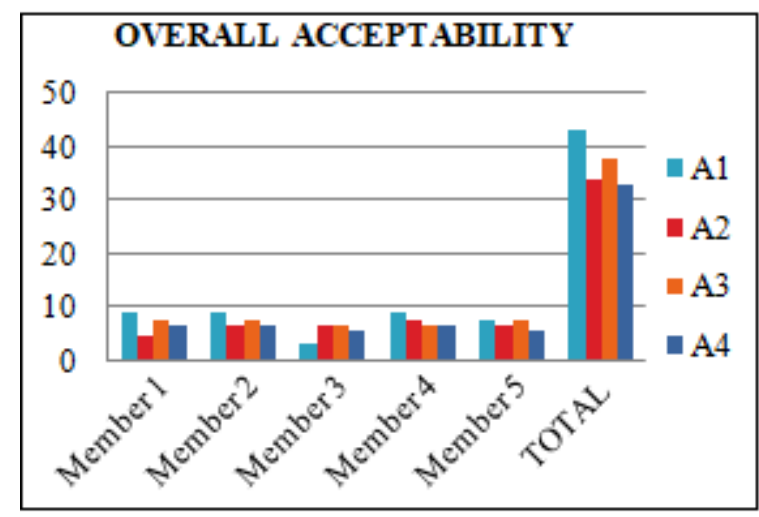

Figure: Graphical Representation of Scores For Overall Acceptability

The overall acceptability graph represents the acceptance on the basis of all the mentioned parameters, the maximum average scored is 43 by the blended beverages A1.Overall acceptability considering flavor and texture there were significant difference among the juices from four samples and sample and 3 was the best.

\section{Overall Calculation}

\begin{tabular}{|c|c|c|c|c|}
\hline Parameters & A1 & A2 & A3 & A4 \\
\hline 1 & 42 & 34 & 38 & 36 \\
\hline 2 & 40 & 34 & 38 & 31 \\
\hline 3 & 43 & 36 & 36 & 34 \\
\hline 4 & 43 & 34 & 38 & 33 \\
\hline Total & 171 & 138 & 150 & 134 \\
\hline Average & 42.75 & 34.5 & 37.5 & 33.5 \\
\hline Standard Deviation & 1.414214 & 1 & 1 & 2.081666 \\
\hline
\end{tabular}

\section{Summary and Conclusion}

The experiment was conducted in the laboratory of Department of Food Science and Technology, School for Home Science, Babasaheb Bhimrao Ambedkar University, Lucknow. The develop mixed fruit and vegetable juice from locally available vegetables and fruit assess the quality in respect of consumer's acceptability and storage ability. The fruit and vegetables used for the preparation of juice were Orange, Tomato, Carrot, and Pineapple.

The chemical analysis (vitamin C, Potassium) of the prepared juice was done at an interval of 60 days. Change in chemical constituents except vitamin $\mathrm{C}$ was observed in the prepared juice throughout the 60 days storage period. There was slight variation in color and flavor in prepared juice from four samples during 60 days storage. Color was found yellow in vegetable juice on the day of preparation and at the end of storage period, the color of juice became fade. Regarding the retention of color and physio-chemical properties storage at refrigeration temperature is better.

Sensory evaluation showed that there were no significant difference among the juices from four samples considering color and overall acceptability. But considering flavor and texture there were significant difference among the juices from three samples and sample 3 was the best.

\section{References}

[1] EI-Nemr SE, Ismail IA, Askar A 1989: Aroma changes in tomato juice during processing and storage. Food chemistry 30(4). pp. 269-275.

[2] Cruess WV 2001: Commercial Fruit and vegetable products. 4th edition. McGrew-Hill Book Co., Inc., USA, pp. 3-38.

[3] Anonymous 2010: A project report on studies of processing and preservation of pineapple juice. Department of Food Technology and Rural Industries, Bangladesh Agricultural University, Mymensingh, pp. 2-3.

[4] Chinprahast N, Tangsuphoom N, Prairahong P, Duangrat V 2002: Mixed vegetables and fruit high jelly drink. J. Agril. Sci. 35(20). pp. 213-222.

[5] Kaur C.; Kapoor H. C Antioxidants in fruits and vegetables - The millennium's health Int. J. Food Sci. Technol .2001,36,703,725.

[6] Rebecca L. Surles, NingWeng,and Philipp W. Simon,Carotenoid Profiles and Consumer Sensory Evaluation of Specialty Carrots (Daucuscarota, L.) of Various Colors, J. Agric. Food Chem. 2004, 52, $3417-$ 34213417.

[7] Nafiseh Zamindar1,MahsaSadrarham andMonirDoudi, Antifungal activity of coriander (Coriandrumsativum L.) essential oil in tomato juices, Received: 15 June 2015 / Accepted: 25 April 2016.

[8] Leah T Coles and Peter M Clifton, Effect of beetroot juice on lowering blood pressure in free-living, Coles and Clifton Nutrition Journal 2012, 11:106.

[9] Bhupinder Singh \&Bahadur Singh Hathan, Chemical composition, functional properties and processing of Beetroot,International Journal of Scientific \& Engineering Research, Volume 5, Issue 1, January2014.

[10] Flaumenbaum BL, Titova AG 2010: Production of natural fruit and vegetable juice with pulp (Union of Soviet Sosialist Republics Odesskii Tekhnologicheskii InstitutePishchevoi Promyshle nnosfiim. M. V. Lomonosova) USSR Patent SU 1706530. 